\title{
An Unusual Kind of Herniation: A Case Report
}

\author{
Murat Ferhat Ferhatoglu* \\ Okan University, Faculty of Medicine, Department of General Surgery, Istanbul, Turkey \\ *Corresponding author: ferhatferhatoglu@yahoo.co.uk
}

\begin{abstract}
Abdominal wall hernias are one of the most common reason for surgery globally. Spigelian hernia is a rare kind of this disease with an incidence of less than $2 \%$. Because of its unic anatomical characteristics, it can be misdiagnosed or overlooked by physicians. Developments in radiological diagnostic tools facilitate correct and early diagnosis. Herein we presented a 76 year-old Spigelian hernia case and discussed anatomical characteristics, diagnosis and treatment methods of this rare kind of hernia with the literature knowledge.
\end{abstract}

Keywords: Hernia, incarceration, Spigelian, Spigelian hernia

Cite This Article: Murat Ferhat Ferhatoglu, “An Unusual Kind of Herniation: A Case Report." American Journal of Medical Case Reports, vol. 6, no. 2 (2018): 36-38. doi: 10.12691/ajmcr-6-2-7.

\section{Introduction}

Abdominal wall hernias are the most common cause of surgical intervention in people over 50 years of age [1]. The most frequent subtypes of this disease with a global incidence of $4-5 \%$ include inguinal hernias (75\%), femoral hernias $(15 \%)$ and umbilical hernias ( $8 \%)$, respectively [2]. Spigelian hernia (SH) has an incidence of $0.12-2 \%$ and are extremely rare [3]. SH was described firstly by the anatomist Joeseph Klinkosch in 1764. Herniation usually occurs through the junction point of semilunar and arcuate lines. The deficiency of the posterior layer of the rectus muscle fascia at this junction point renders this field one of the weakest points of the abdominal wall [4]. The diagnosis of $\mathrm{SH}$ is usually delayed due to its non-specific symptoms and signs.

\section{Case}

A 76-year-old female patient with known chronic obstructive pulmonary disease (COPD), coronary artery disease $(\mathrm{CAD})$ and morbid obesity $\left(\mathrm{BMI}=46.6 \mathrm{~kg} / \mathrm{m}^{2}\right)$ was admitted to the emergency department with the complaints of cramping abdominal pain, nausea and vomiting which had been present for three days. The blood pressure of the patient who was on acetylsalicylic acid $100 \mathrm{mg}$, salbutamol $200 \mathrm{mcg}$, valsartan $160 \mathrm{mg}$, hydrochlorothiazide $25 \mathrm{mg}$ treatment due to COPD and CAD was $155 / 90 \mathrm{mmHg}$. Her heart rate was $78 / \mathrm{bpm}$ and her body temperature was $37.2^{\circ} \mathrm{C}$. A painful, non-reducing mass measuring $5 \times 4 \mathrm{~cm}$ in size was palpated in the left lower quadrant of the patient. The abdominal x-ray of the patient showed air-fluid levels and $\mathrm{CBC}$ revealed no additional pathology except for WBC: $10550 / \mathrm{mm}^{3}$ (4600-10200 / $\mathrm{mm}^{3}$ ). A hernia protruding through the Spigelian fascia and extending between the internal and external oblique abdominal muscles was visualized in the computerized tomography (Figure 1). It was observed that there was some omentum within the hernia sac of the patient who underwent emergency surgery with the pre-diagnosis of incarcerated $\mathrm{SH}$, however, its blood flow was not disturbed (Figure 2). The hernia defect was repaired with a polypropylene mesh measuring $15 \times 15 \mathrm{~cm}$ after the content of the hernia sac was reduced into the abdomen. Oral diet was initiated for the patient who passed gas and stool on postoperative day 1 , and she was discharged on postoperative day 3 . No pathological finding was observed in the patient who came for control visit after one week following the discharge.

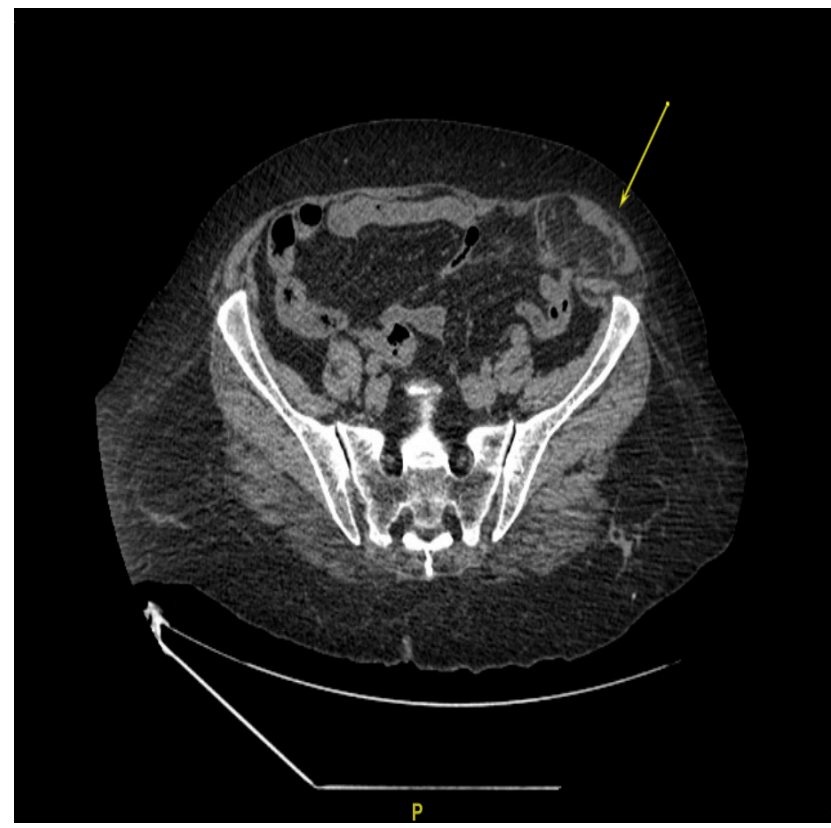

Figure 1. Hernia emerging from Spigelian fascia(Yellow arrow) 


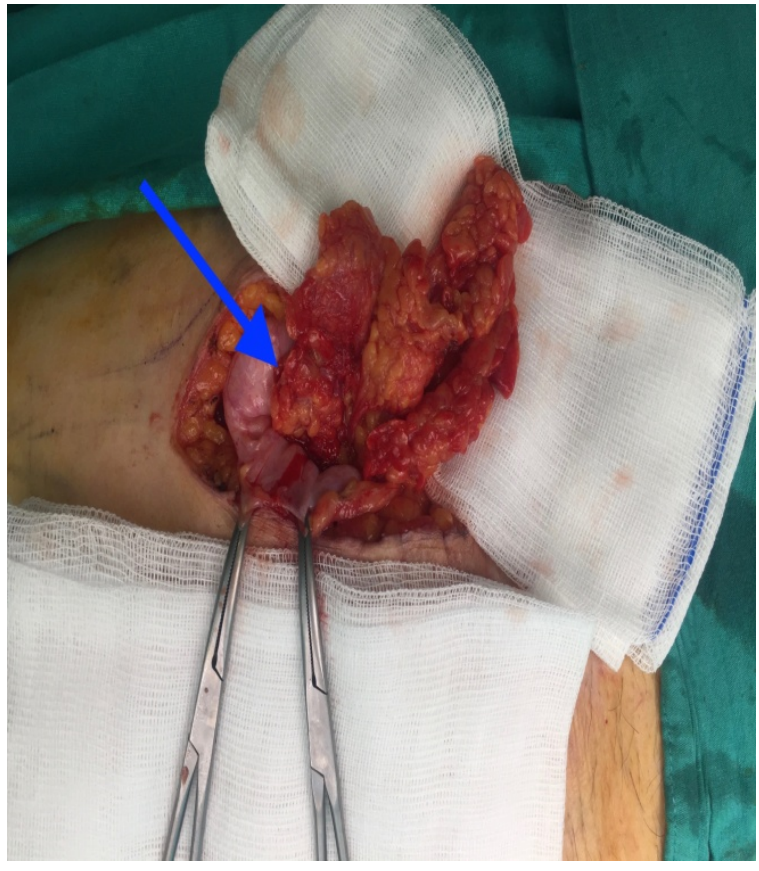

Figure 2. Omentum arising from fascia defect (Bule arrow)

\section{Discussion}

SH usually occurs between the $4^{\text {th }}$ and $7^{\text {th }}$ decades of life and in females [4,5]. Omentum, preperitoneal fatty tissues, small intestines and colon are usually observed within the hernia sac. The cases with SH containing appendix, gallbladder, stomach Meckel diverticulum and ovary as henia content were reported previously [4]. Our case was a 76-year-old woman and there was omentum within the hernia sac.

The risk factors for the development of $\mathrm{SH}$ include obesity, chronic obstructive pulmonary disease and chronic cough, previous abdominal surgery, heavy sports activity, pregnancy and drains-laparoscopic ports inserted at the level of semilunar line are the risk factors for the development of SH [6]. Our patient had a body mass index $>40 \mathrm{~kg} / \mathrm{m}^{2}$, and also she had chronic obstructive pulmonary disease.

Almost all of Spigelian hernias occur in the localization adjacent to the junction point of arcuate and semilunar lines where the posterior fascia of the rectus muscle is deficient. This is the largest and weakest area over the Spigelian fascia and it is called the Spigelian hernia belt [6]. The patients hernia was localizied in Spigelian hernia belt.

Since SH is often located between the fascial and / or muscle planes, the hernia sac can be considered as normal subcutaneous fatty tissue, especially in obese patients. Larson et al. reported that $36 \%$ of the patients had no physical examination finding and that $6 \%$ of them had a hernia as an asymptomatic swelling [5]. Abdominal pain is the main symptom in many patients. Our patient had abdominal pain and a palpable, hard, painful mass over the left Spigelian line.

Radiological imaging methods are quite important for the diagnosis of SH because it does not manifest with any physical examination signs in the majority of patients. Ultrasonography is successful at demonstrating the localization, margins, and content of hernia [7]. Computerized tomography allows us to visualize the margins, localization and course of the hernia sac between the fascial and muscular planes whereas the computerized tomography performed by making the patient drink the oral contrast enable us to see the small intestines within the hernia sac. The necessity for waiting the transit time of the oral contrast to the intestines is a disadvantage of this imaging technique. Despite this disadvantage, computerized tomography is the preferred method for imaging due to the complex anatomical characteristics of SH. Magnetic resonance imaging with its high soft tissue resolution, has become more preferable. We suggest that it can be preferred for the diagnosis and management plan of complicated cases with multiple fascial defects. We preferred to evaluate our patient with computerized tomography since she was morbidly obese.

The treatment of this hernia with high risk of strangulation/incarceration is surgery. The most commonly preferred method for the patients who undergo emergency surgery due to incarceration or strangulation is classical open surgical approach [8]. Since the sac of SH can move between the muscular-fascial planes, the surgeon may not be able to find a fascial defect at the point where s/he feels the swelling of hernia. The precise determination of the hernia sac and fascial defect with preoperative radiological examinations reduces the probability of false incision by the surgeon.

A mesh can be used for the repair of hernia or weakened Spigelian fascia, but meshless repair may be preferred for the hernias with incarcerated intestinal content due to their higher incidence of mesh infection [9]. The laparoscopic repair of hernia is another preferred method. This repair can be performed transabdominally or total extraperitoneally. Especially total extraperitoneal approach is preferred in cases that are not operated emergently. Transabdominal laparoscopic approach should be preferred because it allows better evaluation of intestines for the cases with the suspicion of incarceration or strangulation. We preferred open surgical approach under spinal anesthesia since our case had COPD and CAD, and we preferred mesh repair because there was no incarcerated or strangulated intestinal loop within the hernia sac.

\section{Conclusion}

SH is a quite rarely occurring abdominal wall hernia and its risk of complication is higher compared to other abdominal wall hernias. Because of its unique anatomical characteristics, it should be kept in mind that it can be overlooked in physical examination and, in case of suspicion, it should be evaluated with ultrasonography, computerized tomography or magnetic resonance imaging.

\section{Competing Interests}

No conflict of interest was declared by the authors.

\section{Funding}

There is no funding related to this article 


\section{References}

[1] Lassandro F, Iasiello F, Pizza NL, Valente T, Luisa M, di Santo Stefano M, et al. Andominal hernias: Radiological features. World J Gastrointest Endosc. 2011; 3: 110-17.

[2] Digestive diseases in the United States; epidemiology and impact. NIH publication no.94-1447. BETHESDA: NIDDK, 1994. [Accessed on 30/09/2015].

[3] Kelly ME, Courtney D, Mc Dermott FD, Heeney A, Maguire D, Geoghegan JG, Winter DC. Laparoscopic Spigelian Hernia Repair: A Series of 40 Patients. Surg Laparosc Endosc Percutan Tech. $2015 ; 25$.

[4] Bevilacqua M, Ahmed S, Miller M, Sallee D, Angel W. Case of Spigelian hernia with incarcerated appendix. Radiology case 2016; 10: $23-86-9$.
[5] Larson DW, Farley DR. Spigelian hernias: repair and out come For 81 patients World J Surg. 2002; 26: 1277-81.

[6] Skandalakis PN, Zoras O, Skandalakis JE, Mirilas P. Spigelian hernia: surgical anatomy, embryology and technique of repair. Am Surg. 2006; 72: 42-8.

[7] Jamadar DA, Jacobson JA, Morag Y, et al. Sonography of inguinal region hernias. AJR Am J Roentgenol. 2006; 187: 185-90.

[8] Ruiz de la Hermosa A, Amunategui Prats I, Machado Liendo P, et al. Spigelian hernia. Personal experience and review of the literature. Rev Esp Enferm Dig. 2010; 102: 583-6.

[9] Moles Morenilla A, Carrasco L ,Girela E. Open vs. laparoscopic repair of Spigelian hernia. Arch Surg 2002; 137: 1266-8. 